\title{
A REPRESENTAÇÃO DO “OUTRO” EM NATIVE SON
}

\author{
Ívens Matozo Silva ${ }^{1}$
}

Resumo: Recentes estudos vêm demonstrando um crescente interesse sobre o espaço privilegiado da literatura no que tange à representação de vozes minoritárias e a problematização de conflitos relacionados à aceitação da diferença. Nessa perspectiva, destaque é dado ao romance Native son (1940), do escritor afro-americano Richard Wright, por apresentar, através do seu protagonista Bigger Thomas, as vicissitudes impostas à população negra em um contexto social marcado pela violência e a opressão. Assim, o presente trabalho visa desenvolver algumas considerações sobre a representação da experiência negra durante o período da segregação racial presente no romance, assim como procurar apontar as estratégias usadas para problematizar a identidade do seu protagonista. Foram selecionados e analisados fragmentos que evidenciassem o preconceito racial enfrentado pelo protagonista, assim como aspectos relacionados à sua identidade e diferença, visando relacioná-los com os subsídios de leitura selecionados. Para tanto, baseamo-nos nos estudos de Kathryn Woodward (2005), Stuart Hall (2006) e Eric Landowski (2012).

Palavras-chave: Native son. Identidade. Diferença.

Abstract: Recent studies have presented a growing output of publications expressing the privileged place literature has to represent minority voices as well as to bring reflections upon conflicts related to identity and difference. In this context, stands out in the literary scenario the novel Native son (1940), written by the African-American writer Richard Wright, that represents through its protagonist Bigger Thomas, the painful details and psychological problems that characterize the black experience in a social context marked by oppression and violence. So, the present paper aims at developing some considerations about the African-American experience during the racial segregation period depicted in Richard Wright's novel. Also, this work attempts to highlight the strategies presented in the narrative to discuss its protagonist's identity. To do so, we based our analysis on the studies developed by Brookshaw (1983), Bhabha (1998), Hall (2006), Woodward (2009) and Landowski (2012).

Keywords: Native son. Identity. Difference.

Recentes estudos vêm demonstrando um crescente interesse sobre o espaço privilegiado da literatura no que tange à representação de vozes minoritárias e a problematização de conflitos relacionados à identidade e à aceitação da diferença (Hall, 1997, tradução nossa; Paterson, 2007). Nessa

\footnotetext{
${ }^{1}$ Graduando em Letras Inglês e Literaturas de Língua Inglesa na UFSM. Bolsista FAPERGS. Membro do grupo de pesquisa Literatura e Autoritarismo, coordenado pela Prof. ${ }^{a}$ Dr. ${ }^{a}$ Rosani Ketzer Umbach. E-mail: ivens_matozo@hotmail.com
} 
perspectiva, vários escritores passaram a encarar o espaço literário como um importante meio para reagir contra a brutalidade de contextos sociais marcados pela opressão e a violência.

A literatura é um belo exemplo na qual tais características são fortemente enfatizadas. Escritores, como James Baldwin e Maya Angelou, por exemplo, utilizam o espaço literário como uma forma de denúncia de situações opressivas testemunhadas por afro-americanos. É nesse contexto que se destacam as obras do escritor Richard Wright (1908-1960), o qual se tornou reconhecido por ser um dos primeiros escritores afro-americanos a alcançar uma vasta audiência e pela sua crença que a literatura deveria ser um instrumento para o protesto e progresso social.

Com a publicação de seu romance mais famoso, Native son (1940), Wright ganha renome internacional pelas suas ricas descrições da experiência negra em solo norte-americano. O romance centra-se na vida de um jovem negro que enfrenta problemas psicológicos e emocionais em um contexto social marcado pela segregação racial. Além disso, a narrativa nos apresenta uma rica reflexão sobre a pobreza e a procura pelo reconhecimento por aqueles que não figuraram nas promessas de igualdade e prosperidade do American Dream, os "outros" 2.

Nesse prisma, o presente trabalho visa desenvolver algumas considerações sobre a representação da experiência negra durante o período da segregação racial descrita no romance, assim como procurar apontar as estratégias usadas para problematizar a identidade do seu protagonista.

O romance possui como plano de fundo a cidade de Chicago e apresenta como tempo histórico o ano de 1930. A diegese traz como protagonista o personagem Bigger Thomas, um jovem de vinte anos, negro, pobre e com pouco estudo, o qual nos apresenta cronologicamente através dos três capítulos que compõem o livro: fear, flight e fate, as consequências causadas pelo ambiente de terror racial no qual ele vive.

\footnotetext{
${ }^{2} \mathrm{O}$ termo "outro" utilizado nesse artigo segue os estudos desenvolvidos por Eurídice Figueiredo e Maria Bernadette Porto no livro Figurações da Alteridade (2007). Tal termo inclui personagens caracterizados, como índios, mestiços, imigrantes, doentes mentais, indigentes, etc. Entre estes "outros", também está incluso o afro-descendente.
} 
Logo no início da narrativa, podemos perceber o ambiente degradante em que Bigger, sua mãe e mais dois irmãos vivem. O primeiro capítulo, fear, inicia com um longo toque do relógio despertador da família que faz com que todos acordem. Em seguida, descrições do apartamento que eles alugam e das péssimas condições financeiras da família começam a vir à tona.

Ao analisarmos a primeira cena do romance, podemos associar as péssimas condições do apartamento como a personificação da vida dos seus residentes, em outras palavras, a minúscula sala que a família de Bigger Thomas aluga refletiria a falta de perspectiva dos moradores. Através do discurso utilizado pela mãe de Bigger e compartilhado pelos seus filhos, é possível afirmar que eles apenas almejam o pouco que a sociedade branca estava disposta a lhes oferecer.

No entanto, a partir da apresentação dos pensamentos íntimos de Bigger, apresentados pelo narrador heterodiegético, com perspectiva no personagem, observamos que ele possui medo de ter o mesmo destino e modo de encarar a vida como o resto da sua família.

He hated his Family because he knew that they were suffering and that he was powerless to help them. He knew that the moment he allowed himself to feel to its fullness how they lived, the shame and misery of their lives, he would be swept out of himself with fear and despair. So he held toward them an attitude of iron reserve; he lived with them, but behind a wall, a curtain. (WRIGHT, 1994, p. 9)

Percebemos que ao se autodenominar powerless para modificar a falta de perspectiva da vida de sua família, esta caracterizada por sentimentos como fear, despair, shame e misery, fica implícito que Bigger tentará ter um destino diferente da sua mãe e irmãos. Além disso, ao afirmar que no momento em que ele aceitar ter o mesmo destino ou modo de pensar que eles, Bigger se mataria ou mataria alguém. Tal revelação torna-se de suma importância para a compreensão das futuras ações praticadas pelo protagonista ao longo da narrativa.

Durante aquela manhã, antes de ir para uma entrevista de emprego na casa da rica família Dalton, Bigger decide se encontrar com seu amigo Gus. Ao encontrá-lo, ele o obriga a jogar play white, jogo descrito pela voz narrativa 
como: "a game of play-acting in which he and his friends imitate the ways and manners of white folks" (WRIGHT, 1994, p. 18).

No discurso utilizado pelos amigos, verificamos pelo uso do dialeto submisso yassuh, da expressão nigger e pelo uso da ironia ao rirem da sua própria condição social, o ambiente hostil no qual eles cresceram. Além disso, os diálogos entre os amigos também demonstram a ideologia de que a população negra deveria ser eliminada como se combate uma doença contagiosa.

O jogo encerra-se com uma densa reflexão de Bigger sobre as tensões raciais em seu país. Ele pontua, através de uma enumeração de antíteses, que apesar de negros e brancos viverem no mesmo país, suas realidades sociais são completamente diferentes. Tal reflexão o desestabiliza ao refletir sobre o seu futuro:

Goddammit, look! We live here and they live there. We black and they white. They do things and we can't. It's just like living in jail. Half the time I feel like I'm on the outside of the world peeping in through a knot-hole in the fence... [...] Every time I get to thinking about me being black and they being white, me being here and they being there, I feel like something awful's going to happen to me... (Wright, 1994, p. 20-21)

É possível analisar pela enumeração da sua diferença e pelo modo enfático utilizado por ele através da expressão Goddammit, look! que Bigger chama a atenção não somente do seu amigo Gus, mas também do seu narratário sobre a superioridade branca e, principalmente, da situação marginal da população negra.

Sentimentos como ódio, vergonha e frustração - aspectos relacionados à sua identidade negra - acabam sendo reforçados pela mídia no momento em que os dois amigos decidem ir ao cinema assistir o filme "Trade Horn". Os conteúdos das imagens refletem a influência que a mídia possuía em transmitir a ideia da superioridade branca pelo uso dos estereótipos raciais.

De acordo com os estudos de Homi Bhabha (1998), o uso do estereótipo viria a ser compreendidos como uma falsa representação da realidade, pois descreveria uma forma limitada de representação ao negar a diferença do 
Outro. Na mesma linha de raciocínio, David Brookshaw (1983) afirma que o uso do estereótipo seria comparado ao uso de uma "camisa de força", pois representaria uma forma de controle social e, ao mesmo tempo, uma forma de apagamento da individualidade do sujeito.

$\mathrm{Na}$ cena do filme, pessoas brancas são diretamente relacionadas a palavras, como "wealth", "happiness" e "beautiful body". No entanto, no momento em que o filme apresenta a figura de pessoas negras, imediatamente as imagens relacionadas são de "jungle savages", "wild", assim como são feitas referências pejorativas ao continente africano.

Mais adiante na narrativa, Bigger tenta eliminar seus sentimentos de inferioridade e busca seu reconhecimento. Ele acaba obrigando seus amigos Gus, G.H e Jack a participarem de um assalto à loja do "Old Blum", um velho comerciante branco. É interessante salientar que esse episódio é de suma importância pelo fato de apresentar longas descrições da tensão psicológica e da instabilidade emocional do protagonista. Assim, neste momento do romance somos alertados sobre a natureza bipolar de Bigger e das suas múltiplas identidades.

A tensão psicológica descrita pelo narrador entra em choque com a figura de um homem forte e corajoso que Bigger tenta aparentar para seus amigos. No momento em que ele percebe que seu amigo Gus, que antes havia hesitado em participar do roubo iria finalmente concordar em participar, o protagonista o agride em uma tentativa desesperada de cancelar o assalto. Deste modo, esse episódio claramente demonstra a fragilidade psicológica de Bigger e sua dupla identidade - a primeira, caracterizada pelos seus sentimentos de invisibilidade, tensão e instabilidade emocional; a segunda, marcada pela presença da agressividade e de ações violentas.

Kathryn Woodward (2009) nos apresenta várias considerações a respeito da interação entre os conceitos de identidade e diferença. Segundo ela, as identidades são construídas através da relação com outras identidades, apresentando, assim, uma oposição binária. Tal relação colocaria em evidência a presença de um "eu" e um "outro", envolvendo, assim, reivindicações essencialistas sobre quem irá pertencer ou será excluído de um determinado grupo social. 
Dessa forma, a pesquisadora argumenta que a identidade passa a ser marcada pela presença da diferença. Nesse sentido, ela propõe que a identidade seria estabelecida por marcações simbólicas em relação a outras identidades, em outras palavras, representaria quem é excluído ou incluído. Além disso, ela ressalta que a identidade exige a presença de um sistema classificatório que viria a revelar de que forma as relações sociais estão configuradas e divididas em determinado contexto. Segundo a autora:

A diferença é aquilo que separa uma identidade da outra,
estabelecendo distinções [...] no qual as identidades são construídas
por uma clara oposição entre 'nós' e 'eles'. A marcação da diferença
é, assim, o comportamento-chave em qualquer sistema de
classificação. (Woodward, 2009, p. 41)

Assim como Woodward, Stuart Hall (2006) nos apresenta várias questões relacionadas ao sujeito e seu reconhecimento. De acordo com seus estudos, devido às modificações na sociedade e pela fragmentação das paisagens culturais de classe, gênero, raça e sexualidade, por exemplo, estaria ocorrendo uma verdadeira descontinuidade ou ruptura no processo de reconhecimento do sujeito, fato que veio a romper com a concepção de que possuiríamos uma identidade fixa e bem definida.

Nesse sentido, em um mundo caracterizado pela presença de fronteiras dissolvidas e continuidades rompidas, verifica-se uma considerável proliferação de novas posições-de-identidades. Assim, Hall afirma que o sujeito, além de poder assumir diferentes identidades em diferentes momentos, pode apresentar uma identidade que está sempre sendo formada e que ela dependeria diretamente da forma como o sujeito imagina ser visto pelos outros.

Ao associarmos as reflexões acima nos episódios descritos no romance, é perceptível que a identidade de Bigger Thomas é altamente dependente das relações que ele tem com a sociedade branca. Nesse sentido, o protagonista está ciente não somente do valor simbólico dado à sua identidade negra, mas também da sua posição social na sociedade norte-americana, ou seja, a figura de um sujeito marginalizado e inferiorizado. Tais considerações o obrigam a assumir diferentes identidades em diferentes momentos. 
Após uma manhã conturbada com seus amigos, Bigger ultrapassa as fronteiras raciais e se dirige à casa da rica família Dalton. Ao aceitar trabalhar como chofer, percebemos, através dos seus monólogos interiores, um crescimento da tensão da sua dupla identidade e, consequentemente, a exaltação da não aceitação da sua alteridade.

Eric Landowski (2012) argumenta que a alteridade só existe na relação interpessoal entre um "eu" e um "outro" e pressupõe a presença de um grupo de referência que investirá sobre uma pessoa ou grupo minoritário, neste caso o "outro", um conteúdo semântico. Assim, para que haja alteridade, a presença da diferença torna-se de suma importância.

É importante salientar que Landowski chama a atenção para o fato de que o grupo de referência, ao ter uma imagem "hipostasiada, a ser preservada custe o que custar, em sua integridade - ou melhor, em sua pureza original" (Landowski, 2012, p. 9), ao internalizar o uso de estereótipos como a descrição do "outro" ou não aceitar a presença da sua diferença, a alteridade, utilizandose de uma semantização negativa, passa a ser vista como uma ameaça ou uma forma de exclusão.

Percebemos que personagens como Mary Dalton, filha do casal Dalton, e seu namorado, Jan, ao interagirem com Bigger, através de ideologias comunistas e convicções revolucionárias, que eles tentam entender a diferença do protagonista e compreender a sua alteridade. No entanto, ambos falham ao tentar uma aproximação com Bigger pelo fato de não o verem como um ser humano, mas apenas como um experimento social.

No fim do capítulo "fear", Bigger assassina Mary Dalton e passa por uma profunda transformação. Seu "renascimento" ou metamorfose nos revela uma purificação ou liberdade dos sentimentos que antes o atormentavam. Antes do assassinato, o que caracterizava sua identidade era o "medo", a "vergonha" e o "terror". Logo depois, ela passa a ser descrita pelas sensações de "liberdade" e "entusiasmo":

Like a man reborn, he wanted to test and taste each thing now [...] feeling giddy and elated [...] his eyes shone. It was the first time he had ever been in their presence [white men] without feeling fearful [...] he was eager, tremendously excited. (Wright, 1994, p. 125-127) 
Nesse sentido, a morte de Mary proporciona um sentimento passageiro de poder e identidade ao protagonista. Deste modo, com a perda do medo de enfrentar o homem branco, Bigger passa a utilizar o preconceito racial contra a própria sociedade branca.

Ao longo do romance são descritos vários episódios que descrevem as novas atitudes do protagonista: seu plano de colocar a culpa do desaparecimento de Mary em Jan; o seu perfeito comportamento durante os vários interrogatórios do detetive Britten e o plano para conseguir ganhar dinheiro da família Dalton com falsas cartas enviadas pelos supostos sequestradores de Mary. Assim, através destes exemplos, percebemos como a concepção da ideia de superioridade branca é posta em dúvida no romance.

Além dos exemplos expostos, o próprio protagonista satiriza a situação em que está envolvido e comenta: "who on Earth would think that he, a black timid Negro Boy, would murder and burn a rich white girl and would sit and wait for his breakfast like this?" (Wright, 1994, p. 120).

Percebemos também que a cegueira da Sr.a Dalton pode ser interpretada como uma metáfora que representaria a "cegueira" dos demais personagens em relação ao protagonista. Mr. Dalton e Britten, por exemplo, não conseguem ver Bigger além do que é exposto pelos estereótipos raciais e, com isso, eliminam qualquer possibilidade de que o assassinato ou sequestro de Mary fosse planejado por um negro, pois o crime havia sido: "too elaborated to be the work of a Negro mind" (Wright, 1994, p.275).

O segundo capítulo, flight, é marcado pela intensificação das investigações da polícia e, principalmente, pelas várias descrições de preocupação de Bigger. Deste modo, a narrativa passa a apresentar elementos alegóricos que nos auxiliam a perceber a ansiedade do protagonista. Entre esses elementos, destacam-se a fornalha, utilizada para queimar o corpo de Mary, a qual representaria, através das gradações em sua descrição, a perda de controle emocional da situação em que Bigger se encontrava; e a neve, a qual também representaria a angústia de Bigger durante as investigações e o poder que a sociedade branca exercia sobre a negra, uma vez que é através dela que Bigger acaba sendo capturado pela polícia e mandado para a prisão. 
A partir de então, o que observamos no terceiro capítulo, fate, é a luta pela sobrevivência de Bigger, para escapar da morte na cadeira elétrica. Antes do seu julgamento, o narrador nos descreve a fúria da população que pede que ele seja linchado, especialmente por suspeitarem que Mary havia sido estuprada.

Observamos o papel manipulador da mídia sobre a população ao reforçar a presença dos estereótipos raciais. Ela descreve Bigger como um verdadeiro animal selvagem e, apelando para o sentimentalismo, Mary é retratada como uma menina indefesa, vítima da selvageria relacionada à identidade negra.

$\mathrm{He}$ is about five feet, nine inches tall and his skin is exceedingly black. His lower jaw protrudes obnoxiously, reminding one of the jungle beast [...] It is easy to imagine how this man overpowered little Mary Dalton, raped her, murdered her, beheaded her [...] he seems a beast utterly untouched by the softening influences of modern civilization. (WRIGHT, 1994, p. 322-323)

Tentando desesperadamente salvar a vida de Bigger, seu advogado, Max, apresenta um longo discurso no tribunal. Verificamos, no conteúdo apresentado na fala do advogado, uma profunda revisão dos principais temas explorados ao longo do romance. Nesse prisma, Max defende a ideia de que Bigger não é responsável pela morte de Mary Dalton, mas que suas ações seriam o resultado do modo como a sociedade americana tratava as diferenças raciais. De acordo com o advogado: "we [white American society] planned the murder of Mary Dalton" (Wright, 1994, p. 459).

Deste modo, a mensagem que o defensor de Bigger tenta transmitir para o público é que ele apenas gostaria de ter a chance de viver e crescer com a mesma liberdade do resto da população americana. No entanto, por ser negro e excluído, ele acabaria sendo mais uma vítima, assim como a rica Mary Dalton. Portanto, Bigger seria o produto do ambiente opressivo no qual ele foi criado.

Apesar de todos os argumentos expostos por Max, Bigger acaba sendo sentenciado e mandado para a cadeira elétrica. Percebendo que seu destino havia sido traçado, o protagonista finaliza o romance mergulhando em uma inconsciência profunda. Como o romance nos apresenta um final em aberto, é 
possível observar a presença de um paradoxo: Bigger poderia ser interpretado como uma vítima da opressão racial nos Estados Unidos durante o período da segregação racial ou como um herói que desafiou ultrapassar as fronteiras raciais e apresentar à sociedade o modo desumanizador como os americanos costumavam tratar a população negra.

\section{CONSIDERAÇÕES FINAIS}

Através da análise do romance Native son, buscamos desenvolver algumas considerações sobre a representação da experiência negra durante 0 período da segregação racial descrita no romance, assim como procurar apontar as estratégias usadas para problematizar a identidade do seu protagonista.

A longa onomatopeia descrita na cena inicial da narrativa não serve apenas para acordar a família Thomas. O longo som do alarme poderia ser simbolicamente interpretado como um chamado urgente para o leitor e, principalmente, para a sociedade branca acordar do seu profundo sono sobre a brutal realidade das relações raciais no país, assim como um modo para demonstrar a situação degradante dos africanos-americanos na primeira metade do século XX.

O romance apresentou ao longo dos capítulos "fear", "flight" e "fate", um personagem redondo e periférico que representaria, por metonímia, a experiência afro-americana de opressão na América. Tais fatos foram evidenciados pelas situações de perigo, injustiças e humilhações nas quais Bigger enfrentou. Estas acabaram levando-o a adquirir diferentes identidades em diferentes momentos na narrativa, fato que levou seu reconhecimento fragmentado a se tornar um verdadeiro fardo para o protagonista.

Nesse sentido, verificamos a presença de três identidades distintas: a primeira, caracterizada pelo seu sentimento de inferioridade e não reconhecimento com outros membros do seu grupo étnico; a segunda, pelo seu ganho de liberdade e sentimento temporário de reconhecimento através de 
atos brutais de violência e, por fim, a sua total alienação momentos antes da sua execução.

Além de apresentar impecáveis traços naturalistas, o romance descreve um personagem periférico vitimado e influenciado pelo ambiente degradante no qual ele vivia. A narrativa apresenta vários elementos que ajudam o leitor a compreender as ações de Bigger, tais como o tipo de narrador presente na narrativa, os elementos alegóricos, o uso dos estereótipos e a presença da metáfora. Assim, conseguimos compreender os sentimentos íntimos do protagonista e as cruéis consequências da não aceitação da diferença.

Para concluir, é importante frisar que o romance de Richard Wright nos apresenta uma profunda e sensível percepção realista em relação ao outro. Deste modo, a narrativa propõe-nos uma visão crítica sobre a configuração da sociedade americana e uma reflexão sobre o poder devastador do preconceito racial.

\section{REFERÊNCIAS}

BHABHA, Homi. O local da cultura. Tradução de Myriam Ávila; Eliana Lourenço de Lima Reis; Gláucia Renate Gonçalves. Belo Horizonte: Ed. da UFMG, 1998.

FIGUEIREDO, Eurídice; PORTO, Maria Bernadette Velloso. Figurações da alteridade. Rio de Janeiro: EDUFF/ABECAN, 2007.

BROOKSHAW, David. Raça e cor na literatura brasileira. Porto Alegre: Mercado Aberto, 1983.

HALL, Stuart. Representation: cultural representation and signifying practices. London: The Open University, 1997. 2006.

A identidade cultural na pós-modernidade. Rio de Janeiro: DP\&A,

LANDOWSKI, Eric. Presenças do outro: ensaios de sociossemiótica. São Paulo: Perspectiva, 2012.

PATERSON, Janet M. Pensando o conceito de alteridade hoje. Aletria: Revista de Estudos de Literatura, Belo Horizonte, v. 16, n. 1, p. 1-19, 2007.

SILVA, Tomaz Tadeu da. A produção social da identidade e da diferença. In: SILVA, T; HALL, Stuart; WOODWARD, Kathryn. Identidade e diferença: a perspectiva dos estudos culturais. Petrópolis: Vozes, 2009, p. 73-102. 
WOODWARD, Kathryn. Identidade e diferença: uma introdução teórica e conceitual. In: SILVA, T; HALL, Stuart; WOODWARD, Kathryn. Identidade e diferença: a perspectiva dos estudos culturais. Petrópolis: Vozes, 2009, p. 772.

WRIGHT, Richard. Native son. New York: Harper Perennial, 1994. 